\title{
HEATING AND VENTILATION: REQUIREMENTS AND METHODS
}

\author{
BY \\ T. BEDFORD, D.Sc., Ph.D., M.I.Min.E. \\ (Investigator to the Medical Research Council's Industrial Health Research Board; Lecturer \\ in Industrial Physiology, London School of Hygiene and Tropical Medicine)
}

\section{INTRODUCTION}

' Mental anxiety may, perhaps, be considered the most powerful enemy to the duration of human life, and, next to it, defective nutriment, whether in quantity or quality. But after these, no other cause, at least in modern times, appears to have inflicted so great an amount of evil upon the human race as defective Ventilation. ... Thus wrote Dr. D. Boswell Reid in the preface to his 'Illustrations of Theory and Practice of Ventilation.' Reid's book was published just one hundred years ago, but to-day many would still subscribe to his estimate of the great hygienic importance of ventilation.

Ventilation was defined by Reid as connoting the due appropriate supply of air to any apartment. He was mainly concerned with the quantities of fresh air that were necessary, and with the methods by which that air could be supplied; but he had much to say about the chemical and physical properties of the air. He emphasized the need for maintaining adequate warmth, and made pertinent observations concerning the importance of taking air movement into account. Many of the principles clearly enunciated by Reid have been verified or rediscovered by experimenters during the past thirty years. Ventilation is an important branch of industrial hygiene, and it is fitting that in this first year of publication of a new Journal devoted to industrial medicine, which also marks the centenary of the publication of Reid's classic work, tribute should be paid to that great pioneer of the science of ventilation.

As Reid remarked: "Ventilation need not be expected where food, fuel, and clothing are deficient. Heat is still more essential to the human frame than fresh air. . . ' Man can tolerate an impure atmosphere for long periods, but prolonged exposure to extremes of temperature is likely to lead to acute ill-effects.

The amount of fresh air that can be endured indoors during cold weather is dependent on the adequacy of the heating installation. If insufficient provision is made for warming a building ventilation will be restricted during cold weather. In designing a heating system, the engineer must take into account the amount of fresh air that is to be admitted. Heating and ventilation are indissolubly connected, and they must always be considered together.

\section{Legal Requirements}

At the end of the 18th century, Dr. Percival and his colleagues of the Manchester Board of Health found that those who worked in cotton factories were peculiarly disposed to be affected by fevers, and that even where no particular diseases prevailed, those employed in the factories had their constitutions undermined by the close confinement in hot and impure atmospheres. They found also that in well-regulated factories those evils could be in a considerable degree avoided, and they pressed for legislation for the regulation of factories. Following this agitation, the Health and Morals of Apprentices Act, 1802, provided that cotton mills where poor law apprentices were employed should at all times be properly ventilated. That extension of the poor law marked the beginning of factory legislation. Since that time various statutes have contained provisions relating to ventilation and heating.

(i) Factories. The Factories Act, 1937, contains a number of provisions relating to ventilation and heating. In all new workrooms a minimum of 400 cubic feet of air space must be allowed for each person; no space more than 14 feet in height is to be taken into account, so that the minimum floor area per person is nearly 29 square feet. A gallery is deemed a separate room.

Effective and suitable provision must be made for securing and maintaining by the circulation of fresh air in each workroom the adequate ventilation of the room, and for rendering harmless, so far as practicable, all fumes, dust and other impurities that may be injurious to health generated in the course of any process. Standards of adequate ventilation may be prescribed by the Secretary of State. The insertion of the phrase requiring the circulation of fresh air seems to be a recognition of the importance of air movement in ventilation.

There must be effective provision for maintaining 
a reasonable temperature, and no method of heating may be employed which results in the escape into the air of the workroom of injurious or offensive fumes. For sedentary work a minimum temperature is prescribed. The Act states that where a substantial proportion of the work is done sitting and does not involve serious physical effort, a temperature of less than $60^{\circ} \mathrm{F}$. after the first hour of work shall not be deemed a reasonable temperature. In each workroom to which this provision applies a thermometer must be provided and maintained in a suitable position. The Secretary of State may make regulations prescribing standards of reasonable temperature (which may vary from the above standard), and may prohibit the use of methods of heating which in his opinion are likely to be injurious to the persons employed.

It will have been noted that the general ventilation is required to be sufficient to render harmless any fumes (which term specifically includes gases and vapours), dust, or other impurity of industrial origin that may be dangerous to health. It is further required that where such substances are given off to such extent as to be likely to be injurious or offensive, or where there is any substantial quantity of dust of any kind, all practicable measures must be taken to protect employees from inhaling the dust or fume, and to prevent its accumulation. Where practicable, exhaust appliances must be provided and maintained as near as possible to the point of origin of the dust or fume, so as to prevent it entering the air of the workroom.

Apart from the requirement of a minimum temperature of $60^{\circ} \mathrm{F}$. for sedentary workers, no other minimum temperature is prescribed as a general provision, but for specific industries or groups of industries special provisions are made. Thus in laundries, effective steps must be taken, by the employment of fans or otherwise, to regulate the temperature in every ironing room, and to carry away the steam in every washhouse. Workers must be protected from the heat arising from stoves used for heating irons, and no gas iron emitting noxious fumes may be used.

Some industrial processes, notably some in the textile industry, require a high atmospheric humidity for their efficient performance, and it is the practice to moisten the atmosphere artificially to obtain the required degree of humidity. The Cotton Cloth Factories Regulations, 1929, order that no artificial humidification shall be carried out when the wet bulb temperature exceeds $72 \frac{1}{2}^{\circ} \mathrm{F}$., or when the difference between the dry and wet bulb temperatures is less than that specified in the Schedule to the Regulations $\left(2^{\circ}\right.$ at dry bulb temperatures up to $70^{\circ} \mathrm{F}$., and then increasing to $3 \frac{1}{2}^{\circ}$ at $76^{\circ}$ F.). The minimum permissible temperature in a 'humid' shed is $50^{\circ} \mathrm{F}$. during the first half-hour, and $55^{\circ} \mathrm{F}$. thereafter. It is also specified that no person shall be exposed at work to the direct draught from an air inlet, or to any draught at a temperature of less than $50^{\circ} \mathrm{F}$. To ensure a reasonable fresh air supply it is prescribed that in 'humid' sheds the $\mathrm{CO}_{2}$ content of the air may not be more than 8 parts in 10,000 in excess of the proportion present in the outside air; and in 'dry' sheds the excess must not be more than 11 parts in 10,000 .

The Act of 1937 contains somewhat similar provisions for other humid factories-a 'humid factory' being a factory in which atmospheric humidity is artificially produced, by steaming or other means in connection with any textile process. In rooms where certain spinning or combing operations are carried on artificial humidification must cease when the wet-bulb temperature exceeds $80^{\circ} \mathrm{F}$. and in other rooms when it exceeds $72 \frac{1}{2}^{\circ} \mathrm{F}$. Humidification must also cease when the depression of the wet-bulb temperature below the dry bulb figure is less than the minimum prescribed in a Schedule to the Act. The scheduled scale is very similar to that prescribed for cotton cloth factories, viz. a depression of $2^{\circ}$ at temperatures up to $70^{\circ} \mathrm{F}$., with a scale of increasing differences at higher temperatures so that at $86^{\circ} \mathrm{F}$. the depression must be at least $6^{\circ}$, i.e. the wet-bulb temperature must not exceed $80^{\circ} \mathrm{F}$. when the dry-bulb thermometer records $86^{\circ} \mathrm{F}$.

Various regulations for dangerous trades specify the minimum temperatures that must be maintained, set standards of air purity, and require local exhaust ventilation of prescribed efficiency.

(ii) Offices. In the Offices Regulation Bill of 1926 provisions aiming at the prevention of overcrowding and the maintenance of suitable ventilation were included, but the Bill fell through. The definition of ' workplace' in the Public Health Act, 1936, embraces all places of clerical employment and removes all doubt which previously existed as to the extent to which local authorities had control over the conditions in offices. That Act empowers a local authority to take action to prevent insufficient ventilation or uncleanness or obnoxious effluvia in offices. A Ministry of Health Circular (No. 1600, May 1, 1937) reminds local authorities that it is their duty to cause their district to be inspected from time to time for the detection of statutory nuisances, and any authorized officer of the local authority has right of entry to offices at any time. The circular expresses the Minister's opinion that it is of great importance to national health that conditions in offices should not be such as to be prejudicial to the health of the employees, and local authorities are urged to arrange for the systematic inspection of offices in their areas with a view to ascertaining the conditions and the need for improvement.

(iii) Shops. Local authorities are charged with the supervision of working conditions in shops. The Shops Act, 1934, requires that suitable and sufficient means of ventilation shall be provided, and suitable and sufficient ventilation maintained; and that there shall be suitable and sufficient means to provide a reasonable temperature, and that a reasonable temperature shall be maintained.

\section{The Thermal Environment}

Considerable energy changes take place within the living body, all the energy being derived from 
the oxidation of foodstuffs. A man doing moderate work has total energy requirements amounting to roughly 3000 large calories (or about 12,000 B.T.U.) per day. Much of this energy is evolved as heat. Even when the body is at rest and in warm surroundings, the heat production does not fall below a definite minimum level-the basal metabolism. When physical work is being performed the heat production rises. For many tasks the gross mechanical efficiency of the body is of the order of 20 per cent., the remaining 80 per cent. of the energy expended appearing as heat. Thus it is that in a cold environment one can keep warm by taking exercise.

In health, the mouth temperature and the temperature of the deeper tissues vary but slightly. Constancy of the body temperature, in spite of variations in environmental conditions, is achieved partly by the choice of suitable clothing, and partly by the action of physiological mechanisms which regulate (a) the rate of heat production within the body, and (b) the rate of heat loss from the body's surface. The metabolism remains almost steady at a minimum value over a fair range of temperature (roughly $70^{\circ}$ to $85^{\circ} \mathrm{F}$.), and at temperatures above or below this range it increases.

When a freely exposed object is at a temperature above that of its environment, it loses heat (i) by radiation to the surfaces which surround it, (ii) by convection to the surrounding air, and, if its surface is moist, (iii) by evaporation.

The rate of heat loss by radiation depends on the nature of the surfaces (of the cooling object and its surroundings) which are concerned in the radiation exchange, and on the difference between the fourth powers of the absolute temperatures of those surfaces. The rate of heat loss by convection depends on the temperature and velocity of the air, and also on the size and shape of the body. Evaporation is affected by the temperature of the surface and its degree of wetness, and by the temperature, humidity and velocity of the air. The human body loses heat by these different paths, but the rate of loss is largely influenced by vaso-motor control of the skin temperature, and by variations in the rate of insensible perspiration and sweating. In calm air, under comfortable indoor conditions, roughly half the heat loss from the clothed body is by radiation, while convection and evaporation each account for about a quarter of the total loss. Increased air movement increases the loss by convection and reduces that by radiation. At high temperatures evaporation comes more and more into play, until, when the environment is at the same temperature as the body, it is the only mode of heat loss.

The environmental factors which affect the heat loss from the body, and which govern our feelings of warmth, are, then, the temperature, humidity and rate of movement of the air, and the temperature of the walls and other solid surroundings. If the thermal environment is to be completely described all these four factors must be taken into account.
The measurement of thermal conditions is an important part of the investigation of heating and ventilation.

\section{Measurement of Thermal Conditions}

The air temperature is conveniently measured by means of the ordinary mercury-in-glass thermometer. For the determination of atmospheric humidity the sling hygrometer, consisting of wetand dry-bulb thermometers, is a suitable instrument. The wet-bulb temperature is of importance in warm atmospheres, and from the observed dry- and wetbulb temperatures the humidity of the air, relative or absolute, is readily ascertained by reference to psychrometric tables.

Low air velocities such as those commonly encountered indoors are easily measured by means of the kata thermometer (Hill, 1919; Bedford and Warner, 1933). Another valuable instrument for the measurement of low air velocities is the heated thermometer anemometer of Yaglou (1938). The ordinary kata thermometer with its polished glass bulb is susceptible to the influence of radiant heat. The formulae which are used for the calculation of

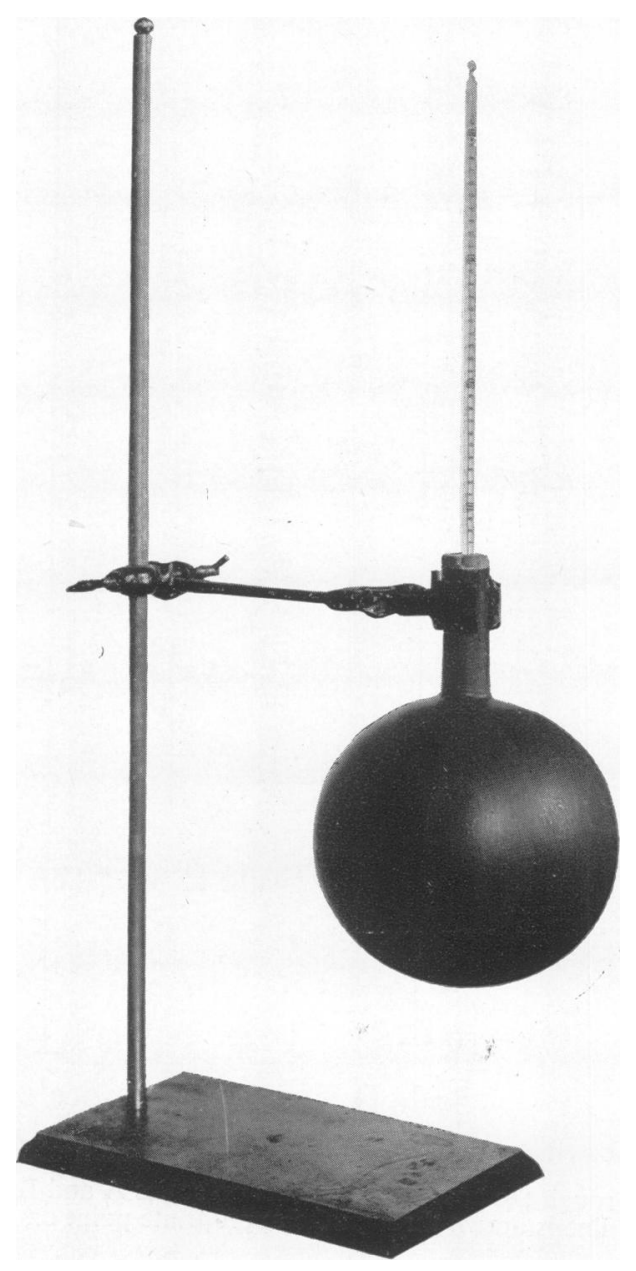

Fig. 1.-The Globe Thermometer. 
air velocities from kata observations contain no term in radiation; it is assumed that the surfaces of the solid surroundings will be at the same temperature as the air. If the temperature of those surfaces is substantially above or below air temperature a corresponding error will be introduced when the air velocity is computed. To overcome this difficulty, Bedford and Warner (1933) advocated the use of kata thermometers with silvered bulbs. The burnished silver surface reflects nearly all the incident radiation, and thus reduces errors from that source to a minimum. The standard kata thermometer has a cooling range of from $100^{\circ}$ to $95^{\circ} \mathrm{F}$., so that if the air temperature is above about $90^{\circ} \mathrm{F}$. observations are either very slow or impossible; indeed, at temperatures above $80^{\circ} \mathrm{F}$. they become tedious. A high temperature kata, with a cooling range of $130^{\circ}$ to $125^{\circ} \mathrm{F}$. is available (silvered or plain) and this is far more convenient to use in hot surroundings.

The radiation from the solid surroundings can be measured by means of a sensitive radiation thermopile used with a suitable galvanometer. The apparatus is costly, however, and many observations are necessary at any one point in order that the radiation from the whole of the surrounding sphere

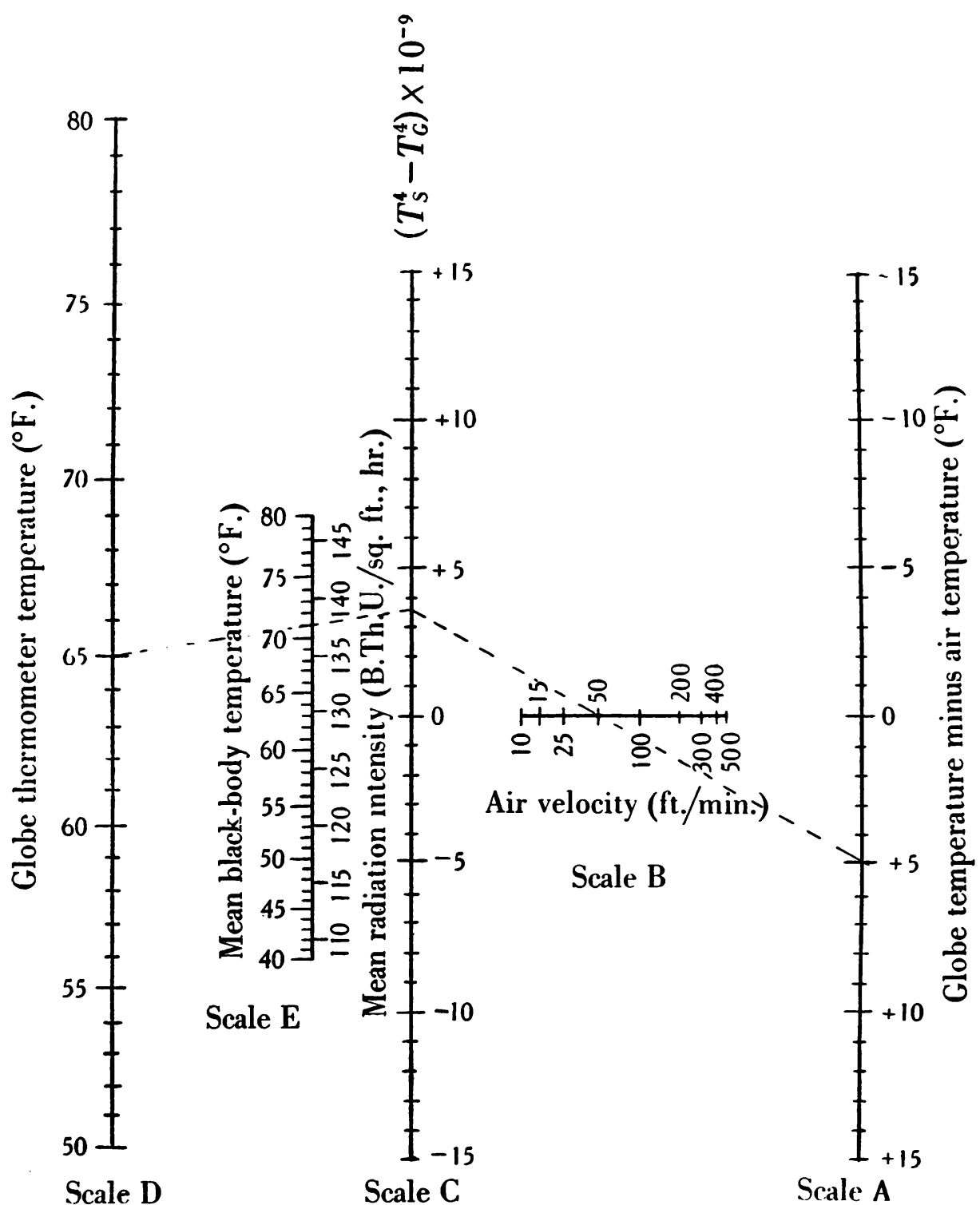

Frg. 2.-Chart for estimation of radiant heat from globe thermometer readings.

(Through the appropriate points on scales A and B a line is struck to cut scale C. From this intersection another line is drawn through the appropriate point on scale $\mathrm{D}$. The intersection on scale $\mathrm{E}$ gives the measure of radiation.) 
can be measured. The mean intensity of radiation, commonly expressed in terms of the mean temperature of the solid surroundings, or, as it is sometimes termed, the mean radiant temperature, can be calculated from readings of Vernon's globe thermometer if the air velocity and air temperature are known. The globe thermometer is a hollow copper sphere 6 inches in diameter, carrying a thermometer with its bulb at the centre of the sphere (fig. 1). The globe is painted matt black, and therefore absorbs virtually all the radiant heat incident upon it. Nomograms which enable the mean temperature of the surroundings to be read off without troublesome calculations have been published (Bedford and Warner, 1934; Bedford, 1937).

For a comparison of thermal environments it is convenient to express the combined effects of the contributory thermal factors in terms of a single index. Such an index is provided by the scale of equivalent warmth derived by Bedford (1936) from the results of a study of the thermal comfort of industrial workers. The equivalent warmth is the temperature of a uniform enclosure, with air and surroundings at the same temperature, and with the air still and saturated with water vapour, which would produce a sensation of warmth equal to that

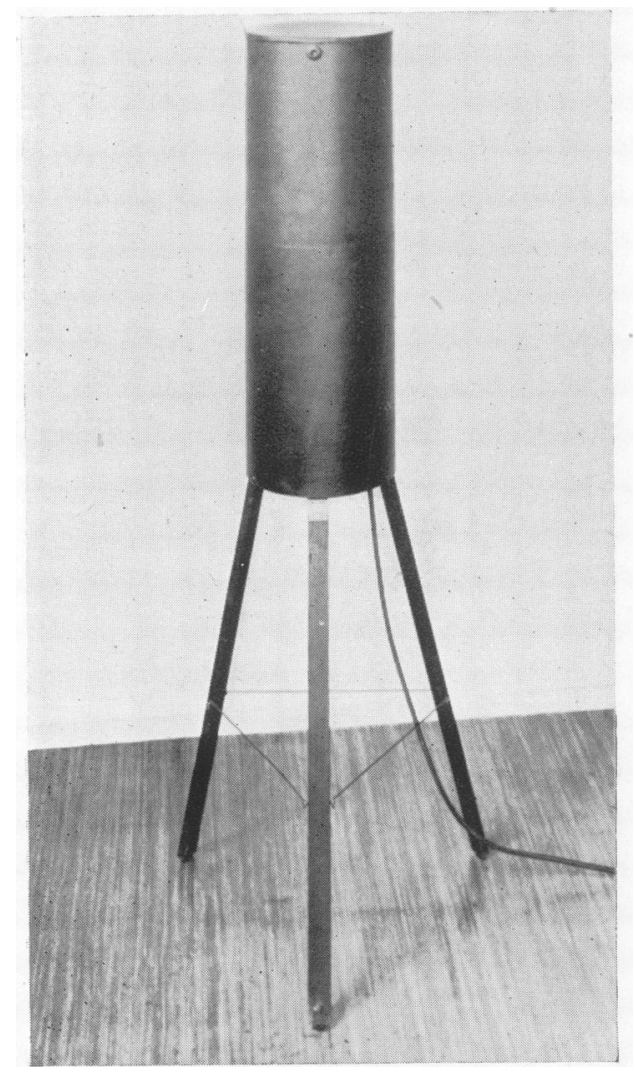

FIG. 3.-The Eupatheoscope. evoked by the combination of radiation and air temperature, velocity. and humidity in question. The range established by that scale is rather limited, and further investigation is necessary to extend it to lower and much higher temperatures.

At temperatures below $65^{\circ}$ or $70^{\circ} \mathrm{F}$. considerable changes in atmospheric humidity have no profound

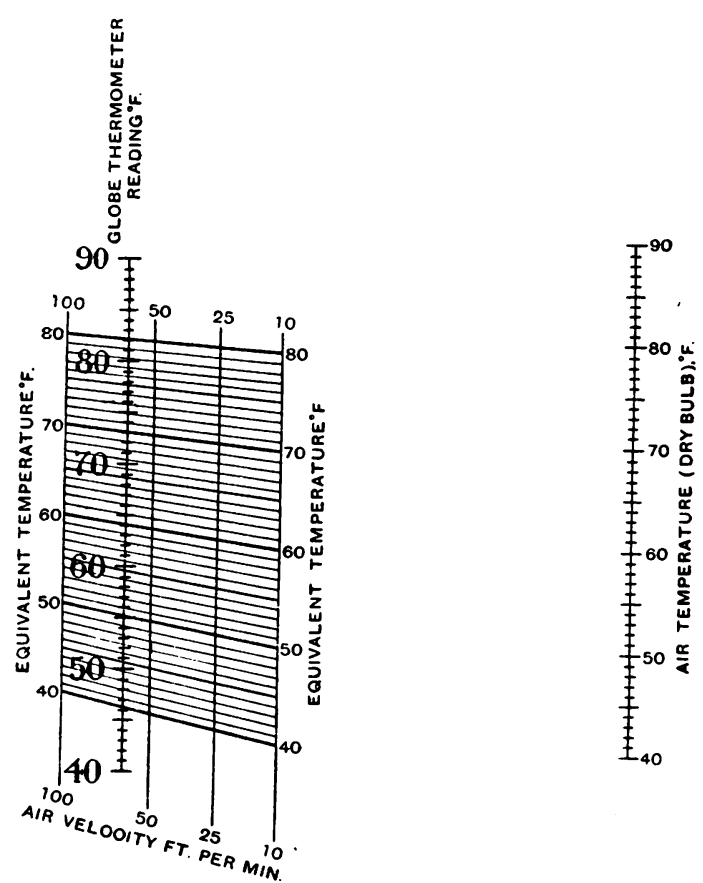

FIG. 4.-Chart for the estimation of equivalent temperature from globe thermometer readings.

effect on feelings of warmth, so that at such temperatures, which are those most commonly encountered indoors in Great Britain, the effects of humidity can be ignored in assessing the warmth of the environment. The remaining three thermal factors, the temperature and rate of movement of the air, and radiation, are taken into account by the scale of equivalent temperature (Dufton, 1932-6). Equivalent temperature is measured by means of an instrument known as the eupatheoscope (or comfort indicator), which is a heated, blackened cylinder, 22 inches high and $7 \frac{1}{2}$ inches in diameter. The heat input is regulated so that, whatever the temperature of the room, the surface temperature of the instrument corresponds with the mean surface temperature of the clothed human body. The equivalent temperature of an environment is that temperature of a uniform enclosure in which, in still air, the body would lose heat at the same rate as in the environment. Equivalent temperature can be estimated from readings of the globe thermometer, the kata thermometer and the ordinary mercury-in-glass thermometer (Bedford, 1936).

When the temperature rises above about $70^{\circ} \mathrm{F}$. 
evaporation from the body surface becomes more important and the humidity of the atmosphere must be taken into account in assessing the warmth of the environment. The scale of warmth most widely used in America, where indoor temperatures are customarily maintained at higher levels than in Great Britain, is known as effective temperature (Yaglou, 1926). This scale takes into account the combined effects of the temperature of the air and of its humidity and rate of movement. Radiation is not specifically taken into consideration. Where the temperature of the solid surroundings is the same as that of the air effective temperature gives an adequate measure of the warmth of the environment, but it is not adequate when those temperatures differ appreciably.

Since the temperature of the globe thermometer is influenced by the air temperature and air velocity as well as by radiant heat, globe thermometer temperatures can also be used as indices of warmth. When Vernon (1932) introduced the glove thermometer it was his intention that it should be so used.

The kata thermometer was also intended primarily as a measure of warmth. The rate of heat loss from its bulb was said to give an indication of the cooling power exerted by the environment on the body. Readings obtained by the dry instrument have therefore been referred to as "dry kata cooling power,' and those obtained when the bulb was covered with a wet finger stall are termed 'wet kata cooling power.' The former takes into account cooling by convection and radiation, while the latter is also influenced by evaporation. The use of the dry kata cooling power for the computation of air velocities is a later development. There are serious physical objections to the kata thermometer as an

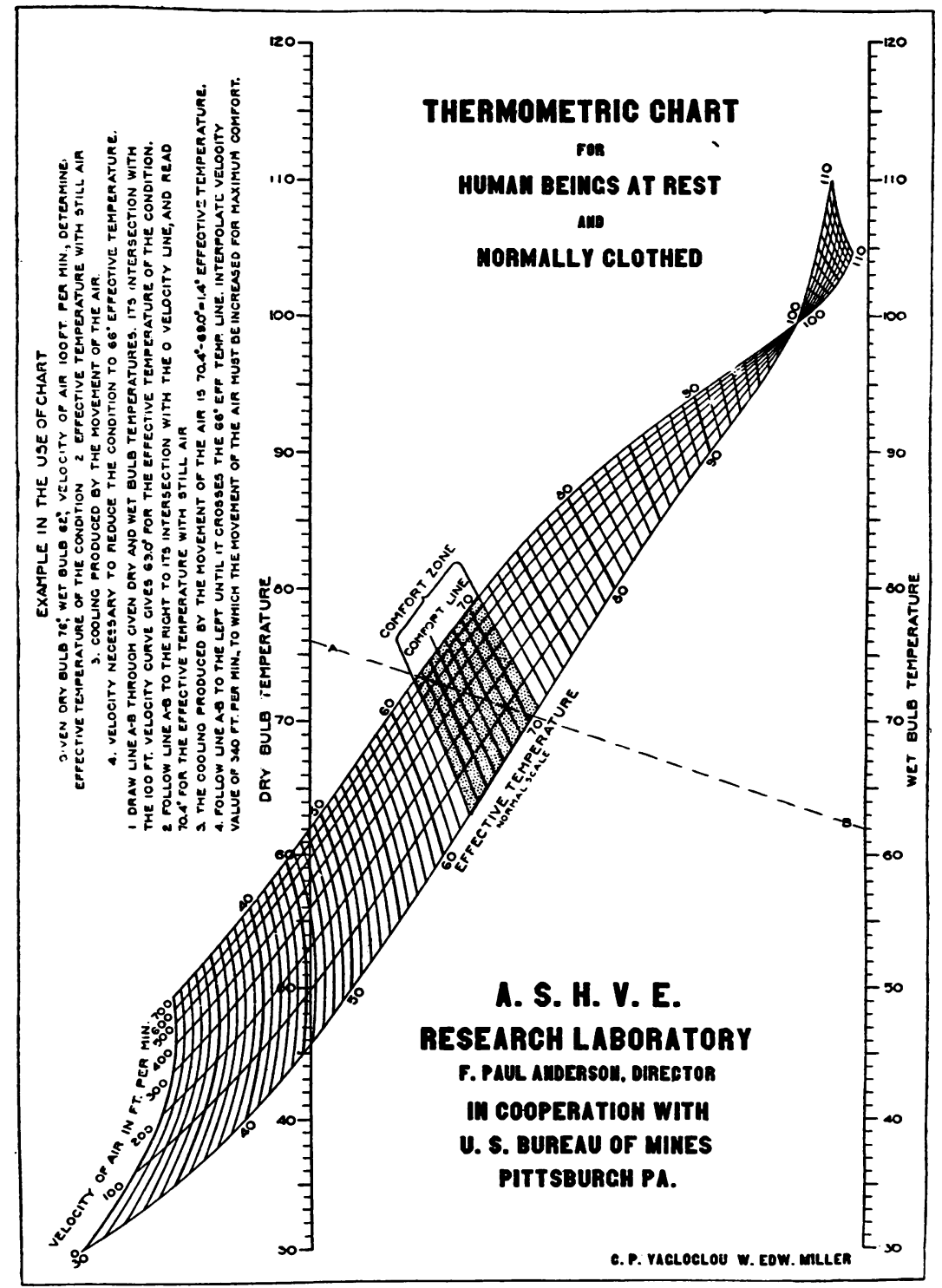

FIG. 5.-Effective temperature chart for persons at rest and normally clothed. 
instrument for indicating the warmth of the environment. The bulb, although large for a thermometer ( $2 \mathrm{~cm}$. diameter and $4 \mathrm{~cm}$. long) is very small in comparison with an object the size of the human body. The convection loss per unit surface area is greatly influenced by the size of the cooling object: the heat loss per square centimetre of surface is much greater in the case of the kata thermometer than in that of the human body, when the temperature difference is the same. For this reason, in comparison with the human body, the kata thermometer is unduly sensitive to changes in air velocity -it makes far too much allowance for convection. This disability as a measure of the overall degree of warmth makes the kata thermometer a very valuable instrument for use as an anemometer.

\section{Warmth and Comfort}

With these various instruments and scales of warmth available, it was obviously desirable that we should know something about their reliability as indices of comfort. An investigation of this problem is reported by Bedford (1936). It was carried out in a number of British factories during the winter months when artificial heating was in use. The subjects were all engaged in light industrial occupations. Ninety-four per cent. of the observations were made on females, and these were mostly young women and girls. At each observation position instrumental measurements of the thermal environment were made, while the workers in the immediate neighbourhood were questioned as to their state of warmth. Measurements were then made of the skin temperatures of the foreheads, hands and feet of the workers, and of the mean surface temperatures of their clothed bodies. In all, over 3000 sets of observations were made. The replies of the workers as to their feelings of warmth were recorded on a seven-point scale of warmth sensations :

1. Much too warm.

2. Too warm.

3. Comfortably warm.

4. Comfortable.

5. Comfortably cool.

6. Too cool.

7. Much too cool.

Statistical examination of the correlation between these 'comfort votes,' as they have been termed, and the various indices of warmth showed that, over the range of environmental conditions covered by the investigation, of the indices taken into consideration equivalent temperature was most closely associated with comfort votes. Globe thermometer temperature was practically as good an index as equivalent temperature, while effective temperature and the dry-bulb temperature of the air were bracketted in the third place. Dry kata cooling power was emphatically a poorer index of warmth than even the simple air temperature.

For the conditions that may be encountered indoors during winter in Great Britain, there can be no doubt that equivalent temperature is the most preferable index of warmth: it makes adequate allowance for radiation and air movement as well as temperature. Where a wide range of air movement may be met with the globe thermometer is at a disadvantage, but in calm air conditions such as usually prevail indoors it is a valuable index. Where any appreciable radiation has to be taken into account, as in the vicinity of high-temperature sources such as open fires, or near large windows or thin, cold walls, equivalent temperature or globe thermometer temperature should be used. But where radiation effects are known to be negligible, as is often the case in a building with convective heating, and where the air is calm, the reading of the much maligned ordinary thermometer is a valuable index.

The feeling of warmth experienced by a person is not dependent solely on the warmth of his environment. Differences in clothing, in muscular activity, in nutrition, age and general bodily build and, not least, in acclimatization, all tend to influence the feelings of warmth experienced by different persons in the same environment. Consequently, it often happens that in a room in which most people are comfortable some feel too warm while others are too cool. Such differences were encountered in the investigation now being described. Measurements of warmth, such as equivalent temperature or air temperature, give a very reliable indication of the average response of a group of people, but they are of little use for predicting the responses of individuals. Similar difficulties experienced by earlier workers led to the suggestion that the temperature of the skin, e.g. of the forehead, would be found to be a better indication of individual comfort, and a good deal of reliance was placed on such measurements by some German researchers. However, this investigation showed quite clearly that skin temperature measurements were unreliable for that purpose.

(i) Winter Temperatures. When one has to prescribe the temperature that is to be maintained in a room where many people are employed, as in a factory or large office, the best that can be done is to ensure the comfort of as many people as possible -it is difficult or impossible to please everybody. Unless the temperature of the building is under automatic control, it is impracticable to keep it exactly at a preordained level day in and day out. Changes in external conditions and the effects of prolonged occupation cause fluctuations, and when manual control has to be relied upon temperature variations will occur. Such variations should be kept within the comfort zone. For persons doing light industrial work during the winter months, Bedford found the comfort zone to range from $58^{\circ}$ to $66^{\circ} \mathrm{F}$. equivalent temperature; from $62^{\circ}$ to $68^{\circ} \mathrm{F}$. as indicated by the globe thermometer; or, in terms of the ordinary air temperature, from $60^{\circ}$ to $68^{\circ} \mathrm{F}$. It is noteworthy that this lower figure of $60^{\circ} \mathrm{F}$. coincides with the minimum temperature prescribed by such workers in the Factories Act.

Persons doing harder physical work do not 
require temperatures as high as those mentioned. It is recommended (Industr. Hlth. Res. Bd., 1940) that for active yet light work the temperature should be between $60^{\circ}$ and $65^{\circ} \mathrm{F}$, and that for work necessitating more muscular exertion it should be $55^{\circ}$ to $60^{\circ} \mathrm{F}$.

(ii) Summer Temperatures. In hot weather it is usually impossible to keep factory temperatures within the limits mentioned above, nor is it desirable that such temperatures should be maintained. In summer we become acclimatized to higher temperatures and make adjustments to clothing, so that temperatures that would be entirely satisfactory in winter would be found chilly in summer. In a wellventilated building it should be possible to keep the temperature to within a degree or two of the outside temperature, unless industrial processes give off much heat.

If a full-scale air-conditioning plant is installed, so that cooling is possible, the temperature should not be lowered too far in the hot weather. Yaglou (1941) has shown that exposure to a sudden temperature drop of $10^{\circ} \mathrm{F}$. or more in hot weather is harmful to a considerable proportion of persons, for the skin and clothing are wet with perspiration and rapid chilling occurs. This initial chilling, which usually lasts only a few minutes, suppresses sweating and may reduce one's ability to withstand heat for some time after returning to the hot atmosphere. For summer air conditioning, dehumidification of the air, with but little reduction of temperature, seems to be indicated.

\section{Draughts}

On the question of what constitutes a draught, as with other questions relating to warmth, there is much divergence of opinion. Some people enjoy and find refreshing cool air currents which provoke others to angry complaint. The velocity at which a current of air becomes noticeable depends on its temperature. At ordinary room temperatures Baetjer (1924) found that currents impinging on the skin of the cheek with velocities below about 40 to 60 feet per minute were not perceptible. But some people complain of draughts when the air velocity is as low as $\mathbf{2 0}$ feet per minute. Investigating such complaints, Bedford (1936) found that those who complained tended to have skin temperatures somewhat below the average, and that, probably partly on that account, they required for comfort an environment about $4^{\circ} \mathrm{F}$. warmer than that found satisfactory by the average person.

\section{Cold Feet}

Chilliness of the feet can be a potent cause of discomfort. About 5 per cent. of Bedford's subjects volunteered complaints of cold feet. Some complained even when the temperature of the air near the floor was nearly $70^{\circ} \mathrm{F}$., but the frequency of complaints increased as the temperature diminished. The complaints could scarcely be ascribed to the effects of strong draughts about the feet, for the air velocity near the floor was less than 50 feet per minute in 88 per cent. of the complaints, and in 45 per cent. it was less than 30 feet per minute. Measurements showed that the feet of the complainants were on the average slightly cooler than those of their fellows, but the difference of $2^{\circ} \mathrm{F}$. was only small in comparison with the variation that was found to occur in foot temperature when air temperature was held constant. Those who complained of cold feet, like those who were upset by draughts, were chilly mortals. For comfort they required a room temperature $5^{\circ} \mathrm{F}$. warmer than that required by the average population. With a given skin temperature they felt cooler than their fellows.

\section{Freshness or Stuffiness}

It often happens that when one has no complaint to make about the warmth of a room, that is, when one is neither too warm nor too cool, one remarks that the room seems stuffy or oppressive, or that it feels fresh and invigorating. Impressions of freshness or stuffiness are not the same as sensations of warmth, and it is necessary to distinguish between them. In two rooms the overall degree of warmth, say the equivalent temperature or the equivalent warmth, may be the same, yet one room may feel fresh and the other stuffy. Feelings of freshness or of stuffiness are mainly conditioned by the thermal environment, and thus they are to some extent correlated with feelings of warmth. On the whole, a cool room tends to feel fresh, while an overheated one feels stuffy. Feelings of warmth depend on the effect of the environment on the heat-regulating mechanism of the body, while sensations of freshness or of stuffiness appear to be evoked by the stimulation or lack of stimulation of the skin by the environment. This stimulation is largely due to air movement, but the other thermal factors also exert their effects.

During the war of 1914-18, the Health of Munition Workers Committee defined an invigorating atmosphere as being: (i) cool rather than hot; (ii) dry rather than damp; (iii) diverse in its temperature in different parts and at different times rather than uniform and monotonous; and (iv) moving rather than still. Sir Leonard Hill had already shown the enervating effects of excessive warmth and humidity and of stagnation of the air.

Vernon, Bedford and Warner (1926), and later Bedford and Warner (1939) studied the effects of the environment on subjective impressions of freshness. From a statistical examination of observational data, and after a discussion of the bearing of other factors not covered by those observations, the latter authors stated the requirements for a pleasant and invigorating atmosphere. These are:

(i) A room should be as cool as is compatible with comfort.

(ii) There should be adequate air movement. At the room temperatures customarily maintained in winter in Great Britain the velocity should be about 30 feet per minute; velocities below 20 feet per 
minute tend to cause feelings of stuffiness. In summer weather, or in hot factories, higher rates of air movement than those mentioned are desirable.

(iii) The air movement should be variable rather than uniform and monotonous, for the body is stimulated by ceaseless change in the environment. Ventilation by open windows is likely to give variable air movement, but in mechanical ventilation installations the inlets should be so designed, and the velocity of discharge so arranged, that suitable eddying currents are set up.

(iv) The relative humidity of the air should not exceed 70 per cent. and should preferably be much below that figure.

(v) The average temperature of the walls and other solid surroundings should not be appreciably lower than that of the air, and should preferably be warmer. The combination of cold walls and warm air often causes feelings of stuffiness.

(vi) The air at head level should not be distinctly warmer than that near the floor, and the heads of the occupants should not be exposed to excessive radiant heat.

(vii) The air should be free from objectionable odours.

It will be noted that variable air movement is specified as desirable. Out of doors we are braced by the changing play of the wind, and indoors, too, the variations of air velocity that occur in a wellventilated room exert a beneficial effect. By means of a hot-wire anemometer, Vernon, Bedford and Warner measured air velocities at $2 \frac{1}{2}$ seconds intervals, and their results clearly show that, with a constant average air velocity, increased variability of movement evokes feelings of greater freshness.

Low relative humidities are advocated. It is often thought, especially when buildings are mechanically ventilated, that the air of warmed rooms becomes too dry during the winter. In Great Britain, during cold weather when the water content of the outside air is very low, the relative humidity may be about 30 per cent. or even lower; yet under such conditions the writer has never found evidence that the air was too dry. The New York State Commission on Ventilation (1923, p. 197) found that exposure for 8 hours a day on 5 days a week to an atmosphere at $75^{\circ} \mathrm{F}$. with a relative humidity of 25 per cent. did not produce any demonstrable harmful effects. Liese (1933) reported that at temperatures of $65^{\circ}$ to $69^{\circ} \mathrm{F}$. no discomfort was felt with relative humidities as low as 25 per cent., but that some unpleasantness was experienced when a sudden severe spell reduced the indoor humidity to 12 per cent. It appears from this that the moisture content of the air must be low indeed before any ill-effects are felt.

It is true that recently Winslow, Herrington and Nelbach (1942) have shown that when the vapour pressure falls below 0.4 inch of mercury, there is a distinct drying at the back of the throat. Such drying occurs at temperatures below $53^{\circ} \mathrm{F}$. with any moisture content up to saturation, at $60^{\circ} \mathrm{F}$. with less than 77 per cent. relative humidity, and at temperatures of $70^{\circ}$ and $80^{\circ} \mathrm{F}$. with less than 54 and 39 per cent. humidity respectively. But at the conclusion of their paper these authors remark that although they have demonstrated this drying they have no evidence that it is undesirable. If such drying is harmful, they say, its influence must be present in cold, dry air as well as in hot, dry air.

\section{Fresh Air Requirements}

Under any ordinary conditions of occupation the air of a room is never likely to become vitiated to such an extent that the oxygen content is low enough, or the carbon dioxide content high enough, to occasion discomfort. The old idea that the discomfort experienced in crowded rooms was due to an excess of $\mathrm{CO}_{2}$ is disproved. Ventilation is bad if the $\mathrm{CO}_{2}$ content reaches 0.5 per cent., but $\mathrm{CO}_{2}$ exerts no sensible physiological effect until its concentration is about $2 \frac{1}{2}$ to 3 per cent., when the depth and frequency of respiration become slightly increased. The main discomfort in crowded rooms arises from the thermal effects that have already been discussed, and the maintenance of a suitable physical environment is one of the cardinal requirements of ventilation. But in addition, ventilation is necessary to remove body odours and the organisms discharged by sneezing and coughing, and where toxic dusts, gases or vapours are liberated into the atmosphere the ventilation must also be sufficient to ensure that the concentrations of these substances are kept below their danger thresholds.

\section{Removal of Body Odours}

During the past century standards of the minimum desirable fresh air supply for occupied rooms have been put forward from time to time. Reid (1844) arrived at the figure of 600 cubic feet of fresh air per person per hour. He gave this 'with much diffidence, and only as an approximation.' His estimate was, however, based on ' an extreme variety of experiments made on hundreds of different constitutions,' and in some cases his subjects were enclosed in a cabinet in which the quality and quantity of the air could be controlled. For barrack rooms, Roscoe (1857) and the Barrack and Hospital Commission (1861) recommended 1200 cubic feet per person per hour. De Chaumont (1875) found that odours were only just perceptible when the air supply was 1500 cubic feet per hour, whereas a supply of 3000 cubic feet was necessary to provide an atmosphere not sensibly different from the outside air; he advocated the higher standard.

More recently much research has been done by Yaglou and his colleagues (1936). Again, the absence of disagreeable odours was taken as the criterion of a satisfactory ventilation rate. It was shown that the intensity of body odour depended greatly on the personal habits of the occupants. Abstention from baths during an experimental week caused the fresh air requirements for odour control to increase day by day. Presumably because of differences in personal habits, and in the bathing facilities available, persons of the poorer social 
grades required more fresh air than did those of higher status; and the requirements of school children were commonly greater than those of adults. Yaglou and his associates set out in detail the fresh air requirements for various types of persons, but from their data it can be concluded that, as a round figure, a minimum fresh air supply of about 1000 cubic feet per person per hour is necessary if the concentration of body odours is to be unobjectionable to persons entering from relatively clean air.

Sometimes it is suggested that such a ventilation rate is unnecessarily high, that people commonly like a 'frowst,' and do not object to odours, and that in the interests of economy of heating lower ventilation rates are permitted. People vary in their response to body odours; some do not seem to object to them, while to others they are most objectionable. But even if some people have often through necessity become accustomed to breathing a foul atmosphere, that is no good reason why they should be expected to do so. We have for many years gone to great pains to safeguard our water supplies, and a high standard of purity is demanded in the case of foodstuffs. Surely one has a right to live and work in an atmosphere that is free from objectionable odours.

There is evidence that body odours are undesirable on other than aesthetic grounds. Winslow and Palmer (1915) found that there were substances present in the air of an occupied room which, in some way, and without producing conscious discomfort or detectable physiological symptoms, diminished the appetite for food. Later, Winslow and Herrington (1936) showed a statistically significant reduction of appetite in the presence of odours.

Reid (1844) tells an amusing story to illustrate the effects of ventilation on the appetite. He says:

Some years ago, about 50 members of one of the Royal Society Clubs at Edinburgh, dined in an apartment I had constructed, where, though illuminated by gas, the products of its combustion were essentially excluded, as they were all removed by a ventilating tube connected with, but concealed in, the drop of the gothic pendant in which the central lights were placed. Large quantities of a mild atmosphere were constantly supplied, and passed in quick succession through the apartment throughout the whole evening, the effect being varied from time to time by infusing odoriferous materials, so that the air should imitate successively that of a lavender field, of an orange grove, etc. Nothing very special was noticed during the time of the dinner by the members; but Mr. Barry, of the British Hotel, who provided the dinner, and who, from the members of the club being frequently in the habit of dining at his rooms, was familiar with their constitutions, showed the committee that three times the amount of wines had been taken than was usually consumed by the same party in a room lighted by gas, but not ventilated-that he had been surprised to observe that gentlemen whose usual allowance was two glasses, took, without hesitation, as much as half a bottle-that those who were in the habit of taking half a bottle, took a bottle and a half, and that, in short, he had been compelled twice to send hackneycoaches for additional supplies during dinner, though he had provided a larger supply than usual, considering the circumstances under which the members met.

Minute inquiries afterwards assured me that no headache nor other injurious consequence followed this meeting, nor were any of the members aware, at the moment, that they had partaken more heartily than usual, till Mr. Barry showed them what had taken place. The meeting included individuals of all ages and of extreme variety of occupations, among whom were judges and members of Parliament, medical men and members of the bar, naval and military officers, whose different ages varied as much as their very various professional occupations.

\section{Air Movement}

Increased ventilation commonly means more air movement, though the statement does not apply without exception. In warm weather we throw open our windows to get more air movement. But substantial increases in the ventilation rate are necessary to gain appreciable increments in the air movement. This is shown by observations, as yet unpublished, made by the writer and his colleagues. Thus, in a closed room with less than one air change per hour the velocity was 10 or 11 feet per minute, while to raise the velocity to 20 feet per minute by natural ventilation it was necessary to raise the ventilation rate to twenty air changes per hour. In factories the movement of persons and machinery tends to cause increased air movement, and in a factory building the air will probably not be very stagnant if the fresh air supply reaches the recommended figure. But in summer much more ventilation than that necessary to remove odours is very desirable. Copious ventilation is desirable in summer, on physical grounds as well as for the removal of odours.

\section{Air-borne Infection}

Bacteria-laden droplets discharged in sneezing and coughing may be spread over a distance of 15 feet or so. They vary in size. The larger ones fall to the ground fairly quickly; but the smaller ones fall slowly, and as evaporation reduces their size many become so small that, like fine dust particles, they remain air-borne for considerable periods. Those organisms which reach the floor may survive on dust nuclei which after disturbance may again become suspended in the air.

In recent years renewed atcention has been given to the question of air-borne infection. It has been shown that organisms and viruses released into the air in one part of a building can be recovered in other parts (Wells, 1935; McCoy, 1934 ; Dalla Valle and Hollaender, 1940). Influenza virus has been recovered up to one hour after its suspension (Wells and Brown, 1936). There seems to be no real evidence as to the relative importance of direct droplet infection and air-borne infection in the transmission of respiratory disease, but there is clear evidence that air-borne infection can occur. 
Cruickshank and Muir (1940) believed that an outbreak of streptococcal infection had been aerially spread.

Clearly, then, the concentration of pathogenic organisms in the air of a room should be kept as low as possible. The concentration can be reduced by increased ventilation or by the use of some bactericidal agent. Much work has been devoted to testing the value of ultra-violet light and of various germicidal sprays for aerial disinfection. Discussing the results obtained, Andrewes (1940) remarks that no method for the control of infection is as effective as adequate spacing of individuals combined with adequate ventilation. Methods such as ultra-violet light and mists are, he says, of value only as second-rate substitutes where proper spacing and ventilation cannot be achieved.

\section{Ozone}

Commercial pamphlets have made great claims for ozone as a means of reducing ventilation costs and enhancing health and comfort. Ozone is said to destroy odours and to sterilize the air, and valuable physiological effects have been claimed for it.

Experimenters in the Rand mines could detect no difference in the working capacity or resistance to fatigue, or in various other bodily reactions, when ozone was added to the air (Weiner, 1938). It is difficult to understand how minute traces of ozone could have any sensible effect on the metabolism, as has been claimed, and Weiner's statement seems to dispose of such claims.

Even in very low concentrations ozone is a powerful irritant. Concentrations of 0.1 to 1 part per million irritate the respiratory membranes, and exposure to such concentrations shortens the lives of guinea-pigs. The irritation threshold appears to be about 0.05 part per million, and distinctly lower concentrations do not appear to injure health. The olfactory threshold level for those with a keen sense of smell was confirmed by Witheridge and Yaglou (1939) to be 0.01 part per million parts of air, while 0.015 part per million was detectable by most normal persons. All normal persons objected to 0.1 part per million, and Witheridge and Yaglou recommended that 0.04 part per million should be regarded as the upper permissible limit in occupied rooms.

It was found by Witheridge and Yaglou that ozone in the just-detectable concentration of 0.015 part per million reduced the smell of body odours enough to allow of a reduction of 50 per cent. in the fresh air requirement for odour control. Lower concentrations of ozone were valueless. There is, however, a great difficulty in the way of any application of this finding to secure a reduction of ventilation costs. With a given output of ozone its concentration in the air of a room may vary within wide limits according to the atmospheric humidity. A constant ozone output may yield only a trace of ozone on a humid day, while on a dry day the concentration may be undesirably high. Hence, Witheridge and Yaglou advise that until adequate means for accurately controlling ozone concentrations are available the use of ozone in occupied rooms should be discouraged.

Elford and von den Ende (1942) found that ozone in concentrations not exceeding the upper permissible limit of 0.04 part per million could inactivate certain unprotected organisms in atmospheres of 60 to 90 per cent. relative humidity; but when such bacteria were covered with a protective coating of organic matter, as in the sprays naturally emitted during coughing or sneezing, ozone in permissible concentrations had no significant effect. Inactivation of such protected organisms required ozone concentrations which must be deemed dangerous for long spells of breathing.

This evidence leads to the conclusions that ozone is not a practicable germicide for use in ventilation, and that until its concentration can be accurately controlled it is not suitable for use in combating body odours.

\section{Dusts, Vapours and Gases}

One function of factory ventilation is to remove deleterious gases, vapours or dusts that may escape into the air of a workroom. It should be emphasized, however, that every effort should be made to prevent the dispersion of such substances with the atmosphere. Sometimes this can be done by substituting harmless substances for toxic ones. Where such substitution is impossible, it may be practicable to arrange for the total enclosure of the process, so that there there can be no escape of the deleterious substance. Failing total enclosure, carefully designed local exhaust ventilation will often provide a solution. There are cases where even local exhaust ventilation is not practicable, and then recourse has to be had to increased general ventilation.

When considering general ventilation from this standpoint, it is not sufficient to ensure that the average concentration of the toxic material is below the danger threshold. The concentration in the neighbourhood of the worker is likely to be distinctly higher than that for the room as a whole, and it is the purity of the air breathed by the worker that matters.

A code of maximum permissible concentrations of various atmospheric contaminants is being prepared for the American Standards Association, but the standards used in Massachusetts have already been published by Bowditch and others (1940). Where toxic substances have to be dealt with by general ventilation the fresh air requirements will obviously be governed by the quantities of air necessary to dilute these substances, rather than by those needed for odour control.

\section{Measurement of Fresh Air Supply}

The ventilation rate can be ascertained directly by measuring the flow of air into or out of a room, or indirectly by measuring the change of concentration of some gas or vapour added to the atmosphere.

Direct measurement is usually the method of 
choice when ventilation is by fans. At fan outlets, or at the air inlets or outlets in individual rooms, the velocity of air flow can generally be measured by means of a vane-type anemometer, and thus the quantity of air passing is readily arrived at. When measurements of the flow through ducts are needed they are generally computed from determinations of pressure differences made with Pitot tubes.

In some buildings with natural ventilation, too, direct measurements of ventilation are possible. The velocity of flow through each ventilation opening can be determined by using a vane anemometer, and the area of each opening is easily measured. Thus the rate of air flow (cubic feet per minute) through each opening is known, and it is usually found that the estimates of total flow through inlets and through outlets correspond remarkably well. This method has frequently been used by the writer and his colleagues in factory buildings.

Ventilation rates in small rooms, such as those in dwellings or in some offices, have frequently been estimated from changes in the composition of the air, and most commonly from variations in the carbon dioxide content.

If the only source of added $\mathrm{CO}_{2}$ is the air exhaled by the occupants, and if occupation has been continuous for an hour or two so that the composition of the air has approximately reached its equilibrium level, the ventilation rate can be estimated by measuring the concentration of $\mathrm{CO}_{2}$. For sedentary persons, or those lightly occupied, the $\mathrm{CO}_{2}$ production amounts to about 0.6 cubic feet per hour, and this is the figure commonly assumed in such estimates. If $k$ is the concentration of $\mathrm{CO}_{2}$ in the room (parts in 10,000) the air supply per person, in cubic feet per hour, $a$, is found from the relation

$$
a=\frac{6000}{k-4}
$$

the concentration in the external air being taken as 4 parts in 10,000 .

The result obtained by this method is not likely to be very accurate, but it will give a rough indication of the ventilation rate, and the method has the merit that it can be applied in occupied rooms.

Another method is to discharge into the room a quantity of some gas which is not a normal constituent of the air, and then measure the rate of decay of its concentration as it is diluted by the ventilating current. A convenient way of employing this method is to liberate hydrogen or coal gas, and then to measure its concentration with an electrical instrument known as a katharometer. If the ventilation rate is steady the concentration diminishes exponentially with time. Concentration plotted against time gives a typical die-away curve, while the logarithm of the concentration is linear with respect to time. Ventilation rates ascertained by this method are calculated, and commonly expressed, as the number of air changes per hour. If it is said that the ventilation rate is one air change per hour, it is meant that the volume of air entering and leaving the room during the period of one hour is equal to the cubic capacity of the room. It is not meant that no jot of the original air is left at the end of one hour. After one 'air change' has taken place there remains in the room 36.8 per cent. of the original air. The katharometer method of measuring air change was used by Marley (1935). It has since been employed in an extensive investigation of the ventilation of dwellings by Warner (1940) and by Bedford, Warner and Chrenko (1943).

\section{Methods of Ventilation}

Ventilating systems are divisible into two main groups, natural ventilation systems in which reliance is placed on natural forces without the aid of mechanical power, and mechanical systems in which power is used to drive fans.

\section{Natural Ventilation}

The two natural agencies that bring about natural ventilation are wind pressure and the force of gravity. The wind drives air in through openings on the windward side of the building so that it passes out on the leeward side. Passing over a chimney top or a roof cowl, the wind has an aspirating action on the air within the flue or cowl. Gravity effects are mainly due to temperature differences. Cool and relatively dense air displaces warmer and lighter air, so that convection currents are set up.

An unheated room provided with an open fireplace has a fair measure of ventilation due to the passage of the wind over the chimney, but when a fire is lit in the hearth, and the air in the flue is heated, the convection effect is added to the aspirating influence of the wind, and the ventilation rate is substantially increased. Or take the case of a factory building with roof cowls and with windows in the walls. When, as is usual, the temperature within the factory is above that outside, the warm air inside is displaced by the cool air entering at the windows, and it passes out through the roof cowls. This gravitational effect is supplemented by the influence of the wind.

(i) Window Ventilation. In narrow factory buildings of the width common in the multi-storey type, good cross-ventilation can usually be obtained by the provision of large and suitably placed windows.

Fig. 6 shows a good arrangement of windows in such a factory. The sides are almost wholly of glass, and in each glazed section there is a swivel frame at high level, and a hopper below. The swivel frames are $3 \frac{1}{2} \mathrm{ft}$. by $3 \frac{3}{4} \mathrm{ft}$. in size, and they can be fully opened. The hoppers are $3 \frac{1}{2}$ feet wide and can be opened to a width of 10 inches. A noteworthy feature of the hoppers is that they are fitted with gusset-pieces at the sides: these serve to prevent draughts. It is a useful working rule that the opening area available for natural ventilation should be not less than 5 square feet for every 100 square feet of floor area. In the factory depicted in the figure the area of the window openings is more than 7 square feet per 100 square feet of floor. Measurements made in this factory during 


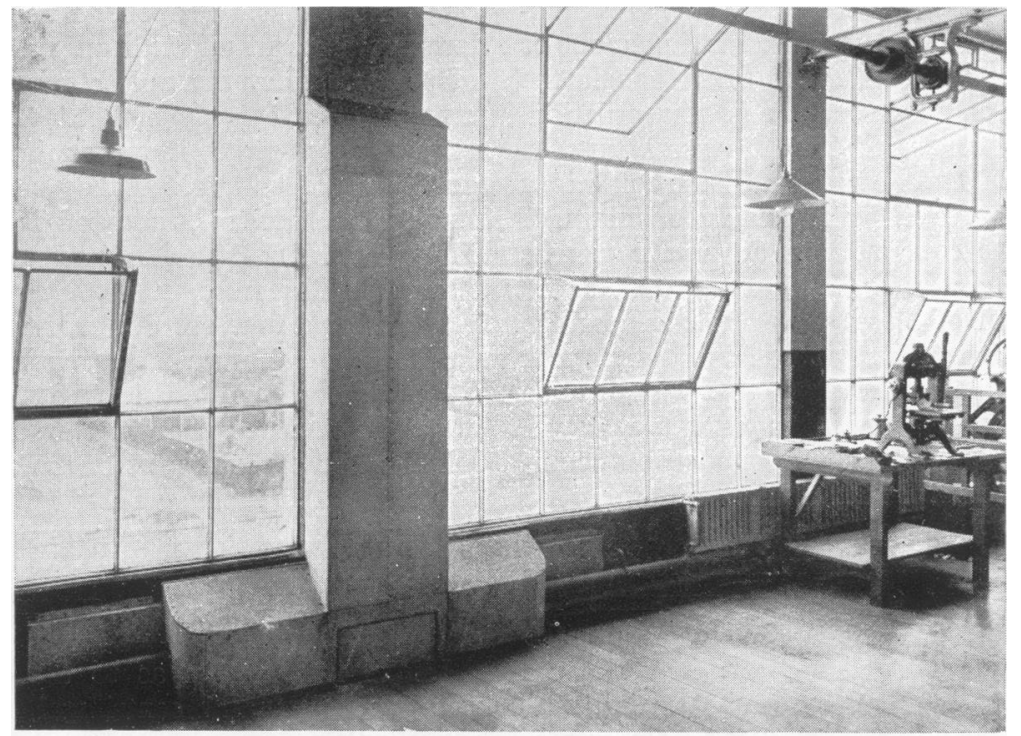

summer weather showed that, with only 40 per cent. of the available window area open, the ventilation rate was twenty air changes per hour, which figure represented a fresh air supply of 12,000 cubic feet per hour per operative (Vernon, Bedford and Warner, 1926b). Judged by the minimum fresh air standard of 1000 cubic feet per person per hour, mentioned earlier, this is lavish ventilation, but the windows were as the operatives had opened them from choice, and the conditions were distinctly pleasant. The air temperature was $68^{\circ} \mathrm{F}$. and the speed of air movement 61 feet per minute.

Between the windows to the left of fig. 6 will be noticed a Tobin tube ventilator. Such air inlets are provided at intervals of $\mathbf{2 0}$ feet along the sides. Inside each tube there is concealed a hot-water radiator, whereby the entering air is warmed in winter, and the inlets are controlled by dampers. By means of these ventilators tempered air can be admitted in winter without the workers experiencing objectionable draughts. Air outlets are provided in the form of air gratings opening into vertical

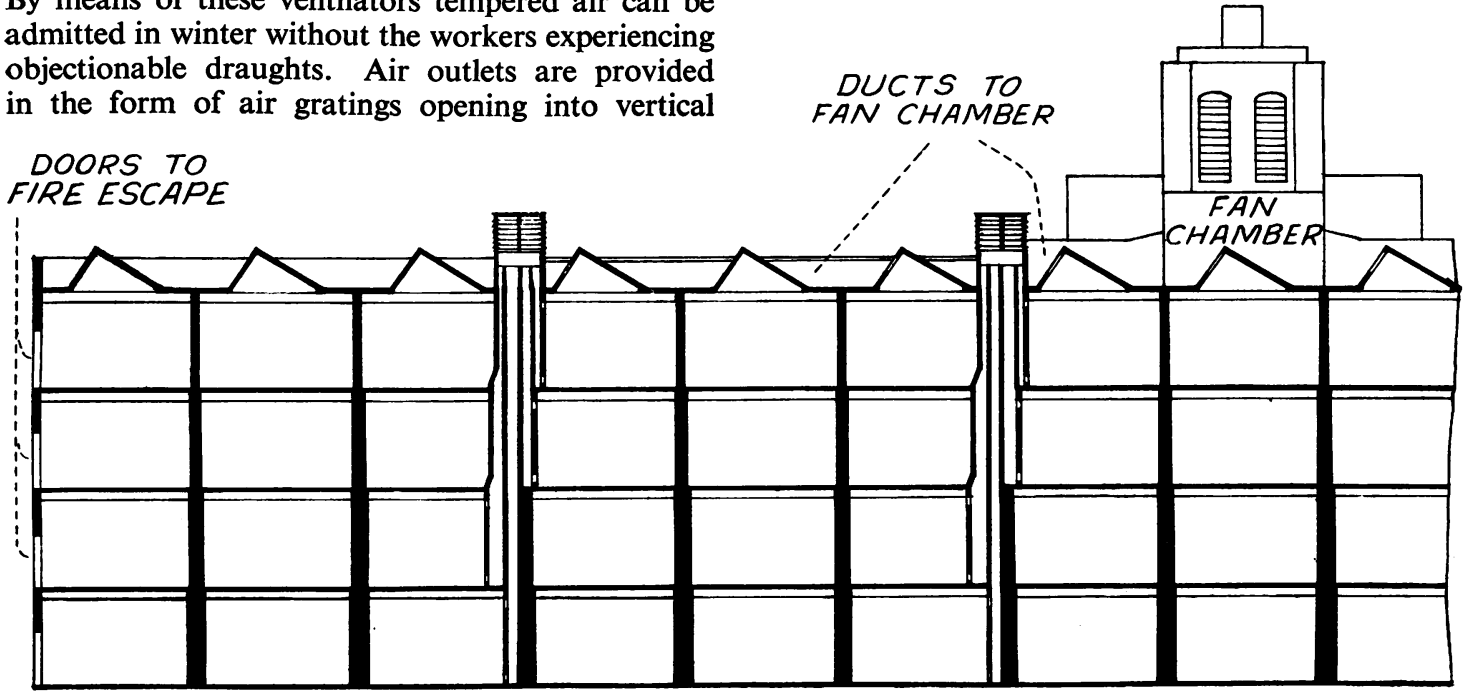

FIG. 7.-Arrangement of exhaust flues.

exhaust shafts. The arrangement of these is shown in fig. 7. There are four large shafts in the middle line of the building, and in each shaft are four separate flues, one from each floor. On the roof, at the top of each shaft, there is a louvred outlet, so that by the combined influence of gravity and the aspirating power of the wind, air is extracted upwards from the workrooms. By means of wire ropes in each workroom flaps are controlled by which any single flue can easily be shut off from the roof louvre and, instead, connected with a horizontal duct that leads to a large centrifugal fan situated beneath an outlet tower. Thus, on occasions when the ventilation by Tobin tubes and gravity exhaust flues is inadequate, and when it is not desired to throw the window open, satisfactory ventilation can be achieved by mechanical extraction. 
In wider buildings, or where proper cross-ventilation is impracticable, window ventilation alone is often inadequate. In such factories though the localities near open windows have good ventilation, there are often considerable ' dead' areas where the air is relatively stagnant. Frequently the conditions can be much improved by providing openings of liberal size in the roof, so that advantage can be taken of gravity effects. Such roof outlets are often in the form of louvres. Double-sided ridge louvres can be made to provide a large outlet area; they suffer from the disadvantage that with adverse winds they may become inlets and the downdraughts thus caused will provoke strong complaints in cold weather. Shutters can be provided so that the louvre facing the wind can be closed, but unless there is careful supervision trouble may still arise. Probably the best arrangement for natural ventilation through roof openings is the provision of modern stationary-type roof cowls. These are so constructed that, whatever the horizontal direction of the wind, they maintain extraction. Such cowls, if of generous size and sufficient in number, can give very satisfactory results when proper arrangements are also made for the entry of fresh air.

Windows of the type illustrated in fig. 6 are excellent for factories of medium or large size, but in small workrooms, such as those found in converted dwelling-houses, good results can be obtained with the ordinary sash-window. In warm weather when the window is opened widely and the door is also open, ventilation will generally be ample. In winter, a fair amount of fresh air can usually be got without serious draughts by employing Hinckes Bird's arrangement. This merely consists of an accurately fitting block of wood, 3 or 4 inches deep, which is inserted below the lower sash. Thus no draught can enter at low level, but air can enter between the sashes and is directed upwards towards the ceiling. This arrangement would be of negligible value in a large workroom, since the amount of air thus admitted would be too small.

In many small rooms such as those just mentioned, and in many offices, chimney flues are provided. A chimney flue of the usual 9 in. by 9 in. crosssection is a valuable ventilating agent even when there is no fire alight at its base, but its ventilating effect is much increased when a fire is burning and the air in the flue thereby heated.

\section{Mechanical Ventilation}

Fans may be used to propel air into a room or to extract it. A system of ventilation in which the air is impelled into the room is known as a plenum or a propulsion system, and when the fans withdraw air from the room the installation is known as an extraction or exhaust system. Either system may be used alone, or the ventilation scheme may incorporate both impulsion and extraction.

The fans used for ventilation purposes are of two main types, propeller or disc fans and centrifugal or pressure fans. Propeller fans are used to move large volumes of air with only a low consumption of power. They are only efficient when the resistance to flow is negligible. They should not, generally, be used to move air through ducts, but if ducts cannot be avoided they should be short, as straight as possible, and of large cross-section. They should not be expected to work against a strong wind pressure.

Centrifugal fans are designed to move comparatively large volumes of air against considerable resistances. They are usually encased in metal and are so constructed that the air enters at a central inlet on one or both sides of the casing, and is discharged tangentially. These pressure fans are commonly employed in plenum ventilation installations, where the air has to be sent through long ducts, and in local exhaust systems for the removal of dust or fumes.

Useful information as to the characteristics of both propeller and centrifugal fans is given in Welfare Pamphlet No. 5, 'Ventilation of Factories,' issued by the Ministry of Labour and National Service.

\section{Extraction Ventilation}

One excellent example of extraction ventilation has been illustrated in fig. 7. This method of ventilation can be used to ensure effective crossventilation in narrow rooms, by placing propeller fans in exhaust openings at suitable intervals in one side wall and providing adequate air inlet opening in the opposite walls. Provision should be made for warming the incoming air, and such provision may well be in the form of the Tobin tubes seen in fig. 6 with radiators encased therein. The air inlets should be of large size, so that the inlet velocities are kept low and draughts thereby avoided. When, as is very often the case, the exhaust fans are mounted in openings in an external wall, they should be protected by wind shields. More effective protection from adverse winds is obtained if the fans discharge into large ducts which are carried vertically some distance above the eaves. If such vertical ducts are taken high enough the action of the wind tends to assist the extraction of air rather than to hinder it.

Extraction fans are often used to ventilate singlestorey factories of small or medium size. Sometimes no suitable provision is made for the entry of air, and the incoming air enters by any available openings or crevices thus creating unpleasant draughts. Care should be taken that proper inlets are provided in positions such that a thorough scavenging of the air of the factory is ensured. Windows and other apertures near the fans should be kept closed, for if they are open the fans will draw their air supply from them and this shortcircuiting will prevent efficient ventilation. Such short-circuiting often occurs. It is not uncommon to find that in a single-storey factory exhaust fans are placed at intervals in the gables, while intermediately there are louvred openings in other 
gables. The fans whirr merrily around, taking their air supply from the near-by louvres, and the workers below are scarcely one whit the better for it.

\section{Plenum Ventilation}

Modern plenum installations, by which air is propelled into the building, afford some advantages over extraction systems. The temperature of the entering air can be controlled, the air can be discharged where it is required, so that even in a large building fresh air can be equally distributed, the air can be filtered or washed as it is taken in, and the slight positive pressure set up by the system prevents the inward leakage of cold air that so often evokes complaints of draughts where extraction systems are employed. The design of a plenum ventilating system is a matter for the expert engineer, since careful computation of duct sizes, fan power and heating load are required. Not least in importance are the situation and design of the air inlets. It sometimes happens that a ventilation system which supplies an adequate amount of fresh air is not so designed as to maintain adequate air movement, or that through faulty design or placing of fresh air inlets people are exposed to most unpleasant draughts. Occasionally it will be found that in factories with elaborate and well-controlled ventilating systems there are, here and there, inlets so placed that to stop draughts workers have stuffed them with sacking. If the velocity of the entering air is too low the atmosphere may feel dead and stagnant in spite of its purity. Excellent results can be achieved by causing the air to issue at high velocity from jets 2 or 3 inches in diameter, of the punkah-louvre type, provided that the direction of discharge is such that nobody works in the line of draught. The turbulence set up by these jets gives the variable air movement that helps to provide an invigorating environment. In many buildings with restricted headroom such jet ventilation is not easy to contrive. In such rooms conical or concentricring deflectors fitted at air inlets can be used to ensure turbulent air movement without undue draughts.

In the older plenum installations the air was driven into the building and allowed to find its way out through any available openings, but nowadays plenum and extraction ventilation are often combined, largely in the interests of economy of heating. It is generally arranged that the plenum fans supply rather more air than is dealt with by the exhaust fans, so that a slight positive pressure is maintained. Such a balanced system is commonly used in air conditioning.

\section{Air Conditioning}

By air conditioning is meant the complete control of the purity, temperature, humidity and cleanliness of the air. It is a combination of ventilation with heating or cooling, and with modern equipment any desired condition of temperature or humidity can be maintained. In some industries, where the processes call for controlled temperature and humidity, or where exceptionally clean air is required, air conditioning is worth while on the score of increased efficiency. But in the climate of this country factory buildings can usually be suitably ventilated by methods which are less costly than full-scale air conditioning, and, in fact, when industrial buildings are air conditioned it is almost invariably for the benefit of the product and not of the worker.

\section{Methods OF Warming}

Heating methods used in buildings are divisible into two groups according as the heat is transmitted mainly by convection or by radiation. In convective warming the air is heated and the structure and contents of the building are warmed by contact with the heated air. With radiant heating, on the other hand, the radiation warms those surfaces on which it impinges, and the air is warmed by contact with those surfaces. Thus, in the case of the familiar open fire, the walls and furniture become warmed by the radiation from the fire and then in their turn impart heat to the air. The chimney breast becomes warmed by the passage of the hot gases up the flue, and that in turn warms the air of the room by convection. At some points in such a room the average intensity of radiation from all directions is such that the mean radiant temperature (or mean temperature of the solid surroundings) is rather higher than the air temperature.

With convection heating, as with so-called hotwater radiators or steam pipes, or, more especially, when warming is by the circulation of heated air, the mean temperature of the surroundings is below the temperature of the air. In some buildings this defect of air temperature below mean radiant temperature is only $3^{\circ}$ or $4^{\circ} \mathrm{F}$. during cold weather, but in thin-walled and thin-roofed structures which are poorly insulated the difference may be much more. As has been remarked earlier, it is undesirable that the temperature of the air should be much above that of the surroundings, and in such cases as those instanced the convective heating should be supplemented with some radiant heat.

Hot air tends to rise, and because of this some methods of air warming produce the undesirable condition in which the air at head level is considerably warmer than that near the floor. Such a condition causes feelings of oppression and stuffiness in the head, while the feet are cold. These temperature gradients are not only a potent source of discomfort; they are wasteful of heat, for the pooling of hot air near the ceiling or in the roof space increases the heat loss from the building. In some factories heating is by steam or hot-water pipes suspended 10 or 12 feet above the floor. The air heated by these pipes rises and tends to pool at the higher levels, and steep temperature gradients are common with this method of heating. If the heat must be supplied in this way, much discomfort could be avoided by arranging that the hot air above the pipes is dispersed by fans and thorough mixing thus 
achieved. Some installations in which hot air is circulated also produce unpleasant temperature gradients. This is especially liable to happen if the fan system discharges a relatively small volume of air heated to a high temperature. It can be stated as a general rule that any air-heating system, whether it be for heating only or for combined heating and ventilation, should discharge a large volume of relatively cool air rather than a small volume of much hotter air. There is much to be said in favour of the modern tendency to supply air at approximately the temperature which it is desired to maintain in the room, and to use radiant heating to compensate for the heat losses from the structure.

Provided that these two important faults, steep temperature gradients and cold walls, etc., are guarded against or compensated for, almost any method of heating can satisfactorily be used to maintain a suitable temperature, so long as the temperature can be kept reasonably uniform throughout the workroom.

In narrow buildings, hot-water pipes or radiators placed along the walls near floor level give excellent results, and with adequate ventilation they produce only slight temperature gradients. Such heating appliances placed higher on the walls, say at head level, cause appreciable gradients of temperature, and are undesirable.

In extensive single-storey buildings unit heaters have been much used in recent years. A unit heater comprises a fan of the open-blade or propeller type, housed usually in a rectangular casing which also contains a heating battery. The fan passes air over the heater and thence propels it through a louvred outlet into the room. The direction of discharge can be altered by adjusting the pitch of the louvres. These heaters possess the advantage that they can be slung from the roof members where desired, and thus they are out of the way of machinery and do not hinder the transit of materials. They are primarily intended merely as a means of heating by warming and recirculating the air within the building. If, however, a short duct is fitted to the intake side of the unit heater it can be made to take fresh air from outside, and it thus becomes a valuable ventilator also. The incorporation of a simple baffle arrangement makes it possible to handle fresh and recirculated air in any desired proportions. Obviously, when the heater is thus connected to the outer air it can be used to impel cool air into the building during summer. If unit heaters are to give satisfaction they should not be run at too high a temperature. They should be installed in sufficient numbers to ensure that overheating of the air will be unnecessary. Properly installed and used these units create beneficial air movement, and maintain pleasant working conditions, but if overrun they may cause dissatisfaction.

Radiant heating may be from low-temperature or high-temperature sources. An example of the former group is the panel-heating that is now frequently used in office buildings, and less often in factories. In some cases hot-water pipes are em- bedded in the ceiling, so that a large proportion of the ceiling area is warmed to about $100^{\circ} \mathrm{F}$. This warmed surface radiates heat downwards and the contents of the room are thereby warmed. There is often some leakage of heat through the floors above, so that the floor also acts as a mild heating surface. Another form of low-temperature panel heating is that in which heated metal plates form part of the wall surface. These wall panels are also effective warming agents. Panel heating causes no appreciable temperature gradients (Vernon, Vernon, and Lorrain-Smith, 1928).

Another system of panel heating consists in the use of small medium- or high-temperature panels heated by electricity. They are about $2 \mathrm{ft}$. by $1 \mathrm{ft}$. in area, and are heated to approximately $500^{\circ} \mathrm{F}$. They are hung in inclined positions so that they radiate across the room in a downward direction. By suitable placing it can be arranged that they give a sensible amount of radiant heat at any position in the room. Unless the room is very lofty they should not be placed horizontally, for the full radiation from such a source when the head is only perhaps 4 feet away is very unpleasant.

Some years ago there was a tendency to use flueless gas heaters in many situations. There was said to be no risk of untoward effects accruing from their use. It should be remembered, however, that these appliances are not always kept in perfect condition, and the possibility that undesirable results may arise from the escape of carbon monoxide, or of sulphur compounds, should be borne in mind.

\section{Thermal Insulation}

Cold walls tend to make a room seem chilly even when the air temperature is such as would ordinarily be found comfortable. Good thermal insulation of the walls and roof not only reduces the loss of heat from a building, but also raises the temperature of the internal wall surface. Thus, good insulation enhances comfort and effects economy of fuel. As Pallot (1943) says, the subject of thermal insulation has not in the past received the attention it deserves. Pallot gives a thorough discussion of the principles of thermal insulation, and instructive examples are contained in Fuel Efficiency Bulletin, No. 12, issued by the Ministry of Fuel and Power. Insulation of thin roofs helps to exclude solar heat, and thus reduce internal temperatures in summer. If the outer roof surface is whitewashed, or otherwise coated with white material, a substantial part of the sun's radiation will be reflected.

In some industries shop temperatures are often needlessly high owing to the heat given off by hot machines or other plant. Great relief to the workers could, in many cases, be obtained by careful insulation of such plant.

\section{SUPERVISION}

In many factories it is nobody's special business to see that proper use is made of such means of heating and ventilation as are provided. Some member or members of the staff should be charged 
with the duty of supervision. Thereby much discomfort would be obviated, and in many cases the loss of efficiency consequent on overheating would be avoided.

\section{Acknowledgments}

Thanks are due to Cambridge University Press for permission to reproduce fig. 2 from the Journal of Hygiene, and to the Institution of Heating and Ventilating Engineers for permission to reproduce fig. 3. Fig. 4 is redrawn from Rept. No. 76 of the Industrial Health Research Board, figs. 6 and 7 are reproduced from Industrial Fatigue Research Board, Rept. No. 35 by permission of the Controller of H.M. Stationery Office. The effective temperature chart (fig. 5) is given by courtesy of the American Society of Heating and Ventilating Engineers.

\section{REFERENCES}

Andrewes, C. H., et al (1940). Lancet, II, Dec. 21, 770. Baetjer, A. M. (1924). Amer. J. Hyg., 4, 650.

Bedford, T. (1936). Industr. Hlth. Res. Bd. Report No. 76.

- (1937). Trans. Instn. Min. Engrs., London, 94, 76.

- and Warner, C. G. (1933). J. Hyg., Cambridge, 33, 330.

-, -二 (1934). Ibid., 34, 458. (in the press).

Bowditch, M., et al (1940). J. Industr. Hyg. \& Toxicol., 22, 251 .

Cruickshank, R. and Muir, C. (1940). Lancet, II, June 29, 1155.

Dallavalle, J. M. and Hollaender, A. (1940). Publ. Hlth. Rep., Washington, July $12,55,1268$.

De Chaumont, F. S. B. F. (1875). Lectures on State Medicine. London: Smith, Elder \& Co.

Dufton, A. F. (1932). Bldg. Res. Bd., London, Tech. Paper No. 13.

- (1936). J. Industr. Heat \& Vent. Engrs., London, $4,227$.

Elford, W. J. and Van den Ende, J. (1942). J. Hyg., Cambridge, 42, 240.

Health of Munition Workers Committee (1918). Final Report, Cmd. 9065.
Hill, L. (1919). Spec. Rep. Ser. Med. Res. Coun., London, No. 32.

Industrial Health Research Board (1940). Emergency Rept. No. 1.

Liese, W. (1933). Dtsch. med. Wschr., 59, 1172

Marley, W. G. (1935). J. Industr. Heat \& Vent. Engrs., London, 2, 499.

McCoy, G. W. (1934). J. Infect. Dis., 55, 156.

Ministry of Fuel and Power (1943). Fuel Efficiency Bulletin, No. 12.

New York State Commission on Ventilation, Report of the (1923). New York: E. P. Dutton \& Co.

Pallot, A. C. (1943). J. Roy. Soc. Arts, 91, 122.

Reid, D. B. (1844). Illustrations of the Theory and Practice of Ventilation. London: Longman, Brown, Green and Longmans.

Roscoe, H. E. (1857). Appendix to Report to the General Board of Health by the Commissioners appointed to inquire into the Warming and Ventilation of Dwellings.

Vernon, H. M. (1932). J. Industr. Hyg., 14, 95

- Bedford, T., and Warner, C. G.' (1926a). Spec. Rep. Ser. Med. Res. Counc., London, No. 100, Pt. III.

$-, \frac{1}{1}, \frac{1}{196 b)}$. Industr. Fatigue Res. Bd. Rept., No. 35.

-, Vernon, M. D., and Lorrain-Smith, I (1928). Industr. Fatigue Res. Bd. Rept., No. 46.

Warner, C. G. (1940). J. Hyg., Cambridge, 40, 125.

Weiner, J. S. (1938). Discussion on paper by E. L. Joseph, J. Instr. Heat \& Vent. Engs., London, 6, 191.

Wells, W. F. (1935). J. Industr. Hyg., 17, 253.

- and Brown, H. W. (1936). Science, July 17, 84, No. $2168,68$.

Winslow, C.-E. A., and Herrington, L. P. (1936). Amer. J. Hyg., 23, 143.

-,,- , and Nelbach, J. H. (1942). I Ibid., 35, 27.

-, and Palmer, G. T. (1915). Proc. Soc. Exp. Biol. \& Med., 12, 141 .

Witheridge, W. N., and Yaglou, C. P. (1939). Heat. Pip. Air Condit., 11, 648.

Yaglou, C. P. (1926). J. Industr. Hyg., 8, 5. (1938). Ibid., 10, 497.

(1941). Suppl. to Amer. J. Publ. Hlth., March, 31. 116. - Riley, E. C., and Coggins, D. I. (1936). Heat.
Pip. Air Condit., 8, 65. 